\title{
Public Health Department Facility
}

National Cancer Institute

\section{Source}

National Cancer Institute. Public Health Department Facility. NCI Thesaurus. Code

C114860.

A healthcare facility that is operated or managed by a local, state or national public health department or program. 